\title{
Characterization and Geographical Classification of Greek Fir Honeys Based on Physicochemical Parameters, Colour Attributes, and Volatile Compounds Using Chemometrics
}

\author{
Ioannis K. Karabagias ${ }^{\mathrm{a}^{*}}$, Evangelia Z. Halatsi ${ }^{\mathrm{a}}$, Stavros Kontakos ${ }^{\mathrm{b}}$, \\ Michael G. Kontominas ${ }^{\mathrm{a}}$ \\ ${ }^{a}$ Laboratory of Food Chemistry Department of Chemistry University of Ioannina, Ioannina 45110, Greece \\ ${ }^{b}$ Democritus University of Thrace, Department of Social Administration and Political Science, Komotini- \\ 69100, Greece
}

\begin{abstract}
The objective of the present study was to characterize commercial fir honey produced in different regions in Greece and investigate the possibility of geographical classification using data sets of physicochemical parameters, colour attributes, and volatile compounds using multivariate analysis techniques. For this purpose, 43 fir honey samples were collected during harvesting periods 2010-2013 from five different regions in Greece. Physicochemical parameters (electrical conductivity, ash, $\mathrm{pH}$, moisture, free acidity, lactonic acidity, total acidity, lactonic to free acidity ratio) were determined using official methods of analysis, while colour attributes $\left(L^{*}, a^{*}, b^{*}\right)$ and browning index were determined using CIE recommendations and methodology published in the literature, respectively. Finally, volatile profiles were determined using headspace solid phase microextraction coupled to gas chromatography/mass spectrometry. Results showed that honey samples analyzed met the criteria set by regulatory standards for fir honey, and exhibited variations in physicochemical parameter values, colour attributes, and volatile profiles, according to geographical origin. On the basis of the results obtained, it is possible to classify (correct prediction 69.8\%) commercial fir honeys produced in specific regions, using a data set of 21 parameters and chemometrics.
\end{abstract}

Keywords: characterization, commercial honey, physicochemical parameters, colour, browning index, volatiles, chemometrics

\section{Introduction}

Apis mellifera honeybees produce honey, a viscous and highly concentrated solution of a complex mixture of sugars, through the collection of nectar from different flowers or honeydew secretions, and the action of enzymes (mainly invertase and glucose oxidase) produced in their hypopharyngeal glands. Honey contains also water and small amounts of other nutrients such as minerals, proteins, vitamins, organic acids, flavonoids, phenolic acids, and other phytochemicals. Phytochemicals have been characterized as health promoting agents and are responsible for the antioxidant activity of honey [1].Honey composition, colour, flavour, as well as the content of phytochemicals depend on the flower sources, geographical origin, climatic conditions, bee species, packaging conditions, thermal and ultrasound treatments, storage time, etc. [1,2]. Variation in honey composition and properties have attracted researchers in conducting a great number of studies, dealing with characterization and authentication [1-5], using instrumental and conventional methods in combination with statistical analyses.

In Greece, previous studies have dealt with the characterization and geographical classification of pine and thyme honeys based on volatile compounds [3] or the combination of physicochemical parameters (including colour) and volatile compounds [2] using chemometrics. Yet, there is no other study involving fir honey geographical classification, using physicochemical parameter, colour attribute, and volatile compound data. Based on the above, the aim of the present study was to investigate if specific physicochemical parameters, including colour, and volatile compounds, could allow the differentiation of fir honey according to geographical origin, using chemometrics.

\subsection{Honey samples}

\section{Experimental}

A total of 43 commercial fir honeys samples were donated by ATTIKI Honey S.A. and local beekeepers, during the harvesting periods 2010-2013, originating from five different regions in Greece: Messinia (7 samples: Abies cephalonica and fir honeydew), Lakonia (11 samples: Abies cephalonica and fir honeydew), Arkadia (9 samples: Abies cephalonica and fir honeydew), Karditsa [12 samples: Abies cephalonica)], and Karpenisi [4 samples: Abies cephalonica)], where fir honey is traditionally produced. The botanical origin of 
honey samples was determined using melissopalynological analysis [2]. Samples were stored in glass containers, shipped to the laboratory and maintained at $4 \pm 1^{\circ} \mathrm{C}$ until analysis.

\subsection{Reagents, solutions, and consumables}

Sodium hydroxide and hydrochloric acid (37\%) used for the determination of free and lactonic acidity were purchased from Sigma Aldrich (Germany). Potassium chloride $(0.1 \mathrm{M})$ was obtained from Hanna (HI 7031, Hanna Instruments, Inc., Woonsocket, USA). Whatman filters (CAT. No. 6780-2504, UK) with a pore size of $0.45 \mu \mathrm{m}$, were used to remove any solid particles prior to spectrophotometric measurements.

\subsection{Physicochemical parameters}

Physicochemical parameters such as electrical conductivity (EC), pH, moisture, free acidity (FA), lactonic acidity (LA), total acidity (TA), as well as the ratio of lactonic to free acidity (LA/FA) were determined according to harmonized methods of international honey commission [6]. The conductivity meter (Delta OHM, model HD 3456.2, Padova, Italy) was calibrated with a $1413 \mu \mathrm{S} / \mathrm{cm}$ standard solution of $0.1 \mathrm{M}$ potassium chloride at $20^{\circ} \mathrm{C}$. Conductivity results were expressed as $\mathrm{mS} / \mathrm{cm}$. Each sample was run in triplicate $(\mathrm{n}=3)$.

\subsection{Determination of ash content}

The ash\%, (w/w) was calculated on the basis of the results of electrical conductivity [7].

\subsection{Determination of colour attributes: $\left(L^{*}, a^{*}, b^{*}\right)$, and browning index}

Colour parameters $\left(L^{*}, a^{*}, b^{*}\right)$ were determined according to CIE recommendations [13], as shown in previous study [10]. Browning index $(\mathrm{BI}), \mathrm{BI}=[100(\mathrm{x}-0.31) / 0.172]$, where $\mathrm{x}=\left(a^{*}+1.75 L^{*}\right) /\left(5.645 L^{*}+a^{*}-3.012 b^{*}\right)$ was estimated according to Ferrari et al.[8]. The results reported are the mean of five determinations $(n=5)$.

\subsection{HS-SPME-GC/MS analysis}

Headspace volatile compounds were extracted from honey, using a divinyl benzene/carboxen /polydimethylsiloxane (DVB/CAR/PDMS) fiber 50/30 $\mu$ m (Supelco, Bellefonte, PA, USA). Prior to use, the fiber was conditioned following the manufacturer's recommendations. Test samples were prepared daily prior to HS-SPME-GC/MS analysis. Blank runs were carried out before sample analysis to make sure that there was no contamination that could cause memory effects. Details on identification, semi-quantification, along with the GC/MS instrumentation and analysis conditions are given in a previous study [2]. Each sample was run in duplicate $(\mathrm{n}=2)$.

\subsection{Statistical Analysis}

In order to test differences between the determined parameters with respect to geographical origin, multivariate analysis of variance (MANOVA) and linear discriminant analysis (LDA) were applied, as previously described [2], to the collected data set. All the statistical treatment of data was performed using the SPSS v.22.0 statistics software.

\subsection{Physicochemical parameters of commercial fir honeys}

\section{Results and discussion}

Water represents the second major constituent of honey. Water content or moisture $(\mathrm{g} / 100 \mathrm{~g})$ is related to different factors such as botanical and geographical origin of the nectar, soil and climatic conditions (rainfall, relative humidity), season of harvesting, degree of maturation, beekeeper's manipulation during period of harvesting, as well as extraction, processing and storage conditions [9]. Honeys from different geographical origin, may have different moisture content, as in the present study. Furthermore, moisture is a quality parameter, related to honey shelf life. In the European regulation [10], the upper limit for moisture content in honey is $20 \mathrm{~g} / 100 \mathrm{~g}$. Higher moisture content may result to an undesirable fermentation, due to the osmophilic (sugar tolerant) yeasts and moulds present in honey. On the other hand, water content may affect several honey properties such as colour, crystallization, viscosity, flavour, and density [11]. The moisture content in honeys analyzed was below $20 \mathrm{~g} / 100 \mathrm{~g}$, in agreement with Turkish, Spanish, and Slovak honeydew honeys, respectively [12-14]

$\mathrm{pH}$ value of honey usually ranges between 3.20 and 4.50 in nectar or blossom honeys and 5.0 to 6.0, in honeydew honeys. Present $\mathrm{pH}$ values were typical of honeydew honeys, being in the range reported previously for honeys originating from Turkey, Spain, and Greece [2, 12, 13].

Electrical conductivity of honey is owed to its ions, organic acids and proteins and is related to the ash content [7]. Thus, the higher the ash content, the higher the resulting conductivity. It is often used as the dominant criterion in the quality control of honey, in order to distinguish between blossom and honeydew honeys. EC values in honeydew honeys should be higher or equal to $0.80 \mathrm{mS} / \mathrm{cm} \mathrm{[10].} \mathrm{All} \mathrm{honeys} \mathrm{analyzed} \mathrm{met}$ this criterion, in agreement with previous studies on honeydew honeys $[2,12,13]$. Ash content $(\mathrm{g} / 100 \mathrm{~g})$ is a measure of quality that evaluates the mineral content present in honey. The mineral content may comprise an indicator of geographical origin or environmental pollution, since mineral content depends on the type of soil used for the growth of plants, having the nectar which honeybees feed on [15].Acidity (meq/ $\mathrm{kg}$ ) is an important parameter related to the freshness and the deterioration of honey. It is characterized by the presence of organic acids in equilibrium with lactones, esters and some inorganic ions (phosphates, sulfates and chlorides) resulting 
to free and lactonic acidity (reverse acidity when honey becomes alkaline). The maximum value for free acidity set by the EU [10] is $50 \mathrm{meq} / \mathrm{kg}$. Higher values may be indicative of undesirable fermentation of sugars into organic acids. However, the presence of different organic acids, geographical origin and harvest season may also affect honey's acidity [15]. FA values were much lower than the upper limit set by the EU [10]. Total acidity (sum of free and lactonic acidity) recorded variations according to the geographical origin of commercial fir honeys (Table 1), but it was lower than $50 \mathrm{meq} / \mathrm{kg}$. Lactonic to free acidity ratio, varied significantly $(p=0.001)$ according to geographical origin of fir honeys. Variations in acidity related parameters have been also previously reported for Turkish, Spanish, Slovak, and Greek honeydew honeys [2, 12, 13, 14].

\subsection{Colour attributes and browning index of commercial fir honeys}

Commission Internationale de l' Eclairage (CIE) system uses three parameters to evaluate colour in foodstuffs: colour parameter $L^{*}$ corresponds to degree of brightness, parameter $a^{*}$ (positive values) corresponds to degree of redness, $a^{*}$ (negative values) to degree of greenness, parameter $b^{*}$ corresponds to yellowness of colour (when positive) and to blueness of colour (when negative) [16]. This system stimulates the human eye observation when irritated with a specific colour. In that sense, honey colour is a very important attribute for consumer product acceptance. The colour of honey may provide useful information, involving: the content of pigments with antioxidant properties (carotenoids, phenolic acids, flavonoids, anthocyanins, etc.), nectar source and pollen content, or mineral content [17]. In addition, processing of honey (i.e. thermal treatment, ultrasonication) may affect honey colour [1].

Results showed that significant differences $(p=0.0024)$ were observed only for colour parameter $a^{*}$ according to geographical origin of commercial fir honeys (Table 1). $L^{*}$ values were higher as compared to the work of Escriche et al. [4] dealing with honeys from Spain, Romania, and Czech Republic (acacia, sunflower, tilia), whereas they were in agreement with previous work on Greek pine ( honeydew) honeys [10]. However, $a^{*}$ and $b^{*}$ colour parameters were much lower as compared to commercial honeys from Thailand and Mexico, respectively $[1,18]$. The browning index $(\mathrm{BI})$ demonstrates the effect of thermal treatments on the development of dark colour in honey samples. The browning reaction could occur as a consequence of increased temperature during honey processing. In the work of Tornuk et al. [15] it was shown that the brown pigment development in honey was correlated to the thermal processing of honey particularly owed to the non-enzymatic browning ( Maillard reaction). On the other hand, the Maillard reaction depends to a great extend, on the presence of high concentration of sugar and amino acids interacting at elevated temperatures. Besides, caramelization of sugars or presence of heat sensitive compounds during thermal processing may increase BI in honey [17]. Present results showed that commercial fir honeys were not thermally treated, since browning index values were much lower as compared to thermally or ultrasound treated commercial honeys [1]. This comprises an additionally quality criterion for fir honey consumers.

Table 1. Physicochemical parameter, colour, and browning index values of commercial fir honeys according to geographical origin

\begin{tabular}{|c|c|c|c|c|c|c|c|c|c|c|c|c|}
\hline Region & $\mathrm{pH}$ & $\begin{array}{l}\text { Free acidity } \\
\text { (meq } / \mathrm{kg} \text { ) }\end{array}$ & $\begin{array}{l}\text { Lactonic acidity } \\
(\mathrm{meq} / \mathrm{kg})\end{array}$ & $\begin{array}{l}\text { Total acidity } \\
\text { (meq } / \mathrm{kg})\end{array}$ & $\begin{array}{l}\text { Electrical } \\
\text { conductivity } \\
(\mathrm{mS} / \mathrm{cm})\end{array}$ & $\begin{array}{l}\text { Moisture } \\
(\mathrm{g} / 100 \mathrm{~g})\end{array}$ & $\begin{array}{l}\text { Ash } \\
(\mathrm{g} / 100 \mathrm{~g})\end{array}$ & L/FA & $L^{*}$ & $a^{*}$ & $b^{*}$ & $\begin{array}{l}\text { Browning } \\
\text { index }\end{array}$ \\
\hline \multicolumn{13}{|l|}{$\begin{array}{l}\text { Messinia } \\
(\mathrm{N}=7)\end{array}$} \\
\hline Mean & 4.85 & 29.46 & 4.77 & 34.23 & 1.25 & 17.70 & 0.75 & 0.17 & 71.21 & -3.93 & 20.62 & 36.19 \\
\hline \pm SD & 0.16 & 4.98 & 0.52 & 4.48 & 0.48 & 0.44 & 0.33 & 0.04 & 1.56 & 2.17 & 4.71 & 9.40 \\
\hline \multicolumn{13}{|l|}{$\begin{array}{l}\text { Lakonia } \\
(\mathrm{N}=11)\end{array}$} \\
\hline Mean & 4.92 & 26.10 & 5.78 & 31.89 & 1.52 & 15.40 & 0.94 & 0.23 & 72.68 & -4.68 & 17.95 & 30.89 \\
\hline$\pm \mathrm{SD}$ & 0.24 & 4.06 & 0.61 & 3.50 & 0.20 & 1.33 & 0.14 & 0.06 & 1.11 & 0.63 & 5.43 & 11.62 \\
\hline \multicolumn{13}{|l|}{$\begin{array}{l}\text { Arkadia } \\
(\mathrm{N}=9)\end{array}$} \\
\hline Mean & 4.80 & 27.71 & 4.84 & 32.56 & 1.83 & 18.59 & 1.15 & 0.18 & 71.45 & -4.73 & 21.77 & 39.50 \\
\hline$\pm \mathrm{SD}$ & 0.11 & 3.74 & 0.37 & 3.38 & 0.48 & 1.38 & 0.32 & 0.04 & 1.97 & 0.60 & 6.29 & 15.77 \\
\hline \multicolumn{13}{|l|}{$\begin{array}{l}\text { Karditsa } \\
(\mathrm{N}=12)\end{array}$} \\
\hline Mean & 5.02 & 30.55 & 4.26 & 34.81 & 1.23 & 17.58 & 0.74 & 0.15 & 69.79 & -3.61 & 24.50 & 50.05 \\
\hline$\pm \mathrm{SD}$ & 0.32 & 6.41 & 0.70 & 5.76 & 0.16 & 1.97 & 0.11 & 0.05 & 3.56 & 0.93 & 9.20 & 26.41 \\
\hline \multicolumn{13}{|l|}{$\begin{array}{l}\text { Karpenisi } \\
(\mathrm{N}=4)\end{array}$} \\
\hline Mean & 4.80 & 33.48 & 3.85 & 37.33 & 1.27 & 16.30 & 0.77 & 0.12 & 70.27 & -3.02 & 20.68 & 38.66 \\
\hline \pm SD & 0.34 & 5.10 & 0.48 & 4.63 & 0.12 & 1.02 & 0.08 & 0.03 & 1.24 & 0.31 & 1.51 & 3.26 \\
\hline
\end{tabular}

$\mathrm{N}$ : number of honey samples. Mean: average value of three $(n=3)$ and five $(n=5)$ determinations for physicochemical and colour parameters, respectively. SD: standard deviation. MANOVA in comparison of means $(p<0.05)$.

\subsection{Volatile compounds of commercial fir honeys}

Forty two volatile compounds (including furfural) were identified and semi-quantified using internal standard (benzophenone) [2]. These compounds belong to different classes: acids, esters, alcohols, aldehydes, ketones, terpenoids, norisoprenoids, hydrocarbons, benzene derivatives, furan derivatives, etc. Table 2 lists the 
15 key volatile compounds which served as markers of geographical origin. Full volatile data is given as supplementary files.

A typical chromatogram of fir honey (no.1) from Karpenisi, pointing out the key volatile markers of geographical origin, numbered according to Table 2, is given in Fig.1. Numerous of these compounds including: 2-ethyl-1-hexanol, 1-octanol, 1-nonanol, furfural, benzaldehyde, octanal, decanal, benzeneacetaldehyde, heptane, 1-octene, octane, nonane, 2,5-dimethyl-furan, borneol, 3,4,5-trimethyl-phenol, have been identified in Greek and Turkish pine honeys [19,20] as well as in fir honeys from Croatia [21]. What is remarkable is that, the ethyl esters identified in the present study, have not been reported previously in monofloral honeys produced in different countries $[3,20,21,22]$. These compounds are reported for the first time in fir honey, and may originate from resins secreted in Greek fir trees. It should be stressed that, honey aroma, along with colour and taste, are among of the most important parameters affecting product acceptability by consumers. Furthermore, numerous volatile markers have been used for the determination of geographical and botanical origin of particular honey samples $[2,3,4,20]$, using chemometrics.

Table 2. Key volatile compounds (mean values, $\mathrm{mg} / \mathrm{kg}$ ) of commercial fir honeys of different geographical origin

\begin{tabular}{|c|c|c|c|c|c|c|c|c|c|c|}
\hline $\begin{array}{l}\text { Number } \\
\text { of compound }\end{array}$ & RT & Volatile compounds & Karditsa & Lakonia & Messinia & Arkadia & Karpenisi & $\mathrm{KI}^{\mathrm{a}}$ & $\begin{array}{l}\text { Method of } \\
\text { identification }{ }^{b}\end{array}$ & $\mathrm{GOM}^{c}$ \\
\hline & & Benzene derivatives & & & & & & & & \\
\hline 1 & 15.10 & ethenyl-benzene & 0.011 & 0.316 & 0.062 & 0.370 & nd & $<800$ & MS & Arkadia \\
\hline \multirow[t]{2}{*}{2} & 18.73 & benzeneacetaldehyde & 0.048 & 0.238 & 0.543 & 0.282 & nd & 1060 & KI/MS & Messinia \\
\hline & & Esters & & & & & & & & \\
\hline 3 & 7.18 & acetic acid ethyl ester & 0.123 & nd & 0.008 & nd & 0.159 & $<800$ & MS & Karpenisi \\
\hline 4 & 21.40 & octanoic acid ethyl ester & 0.622 & 0.986 & 0.910 & 1.00 & 0.083 & 1187 & $\mathrm{KI} / \mathrm{MS}$ & Arkadia \\
\hline 5 & 21.88 & $\begin{array}{l}\text { 2-hydroxy-benzoic acid } \\
\text { methyl ester }\end{array}$ & 0.123 & 0.601 & 0.202 & 0.619 & nd & 1212 & $\mathrm{KI} / \mathrm{MS}$ & Messinia \\
\hline 6 & 23.30 & nonanoic acid ethyl ester & 1.150 & 1.725 & 2.318 & 2.001 & 0.163 & 1286 & $\mathrm{KI} / \mathrm{MS}$ & Messinia \\
\hline \multirow[t]{2}{*}{7} & 26.87 & undecanoic acid ethyl ester & 0.020 & nd & 0.033 & 0.006 & nd & 1491 & $\mathrm{KI} / \mathrm{MS}$ & Messinia \\
\hline & & Hydrocarbons & & & & & & & & \\
\hline 8 & 9.54 & heptane & 0.095 & nd & 0.027 & 0.004 & 0.106 & $<800$ & MS & Karpenisi \\
\hline 9 & 12.08 & 1-octene & 0.023 & 0.378 & 0.103 & 0.454 & 0.026 & $<800$ & MS & Arkadia \\
\hline 10 & 12.33 & octane & 0.699 & 1.584 & 1.997 & 1.978 & 0.291 & 800 & $\mathrm{KI} / \mathrm{MS}$ & Messinia \\
\hline \multirow[t]{2}{*}{11} & 14.94 & nonane & 0.199 & 0.621 & 0.204 & 0.739 & 0.060 & 900 & KI/MS & Arkadia \\
\hline & & Ketones & & & & & & & & \\
\hline 12 & 14.75 & heptanone-2 & 0.017 & nd & nd & nd & nd & 890 & $\mathrm{KI} / \mathrm{MS}$ & Karditsa \\
\hline \multirow[t]{2}{*}{13} & 25.36 & Beta-damascenone & 0.007 & nd & 0.036 & nd & nd & 1401 & $\mathrm{KI} / \mathrm{MS}$ & Messinia \\
\hline & & Norisoprenoids & & & & & & & & \\
\hline \multirow[t]{2}{*}{14} & 20.86 & 4-keto-isophorone & 0.050 & 0.315 & 0.014 & 0.400 & nd & 1161 & $\mathrm{KI} / \mathrm{MS}$ & Arkadia \\
\hline & & Furan compounds & & & & & & & & \\
\hline 15 & 9.54 & 2,5-dimethylfuran & 0.072 & 0.392 & 0.124 & 0.486 & nd & $<800$ & MS & Arkadia \\
\hline
\end{tabular}

RT: retention time ( $\min )$, nd: not detected, every value is the average of two replicates $(\mathrm{n}=2),{ }^{a}$ KI: Experimental Kovats index values using hydrocarbons being naturally present in honey, ${ }^{\mathrm{b}}$ Method of identification: MS, identification by comparison with MS data in Wiley 7 NIST 2005 mass spectral library/ KI, identification by comparison of Kovats index with the literature cited or included in the Wiley library. Class of compounds is presented alphabetically. nd: not detected. GOM: geographical origin marker as defined by comparison of mean values using MANOVA and LDA.

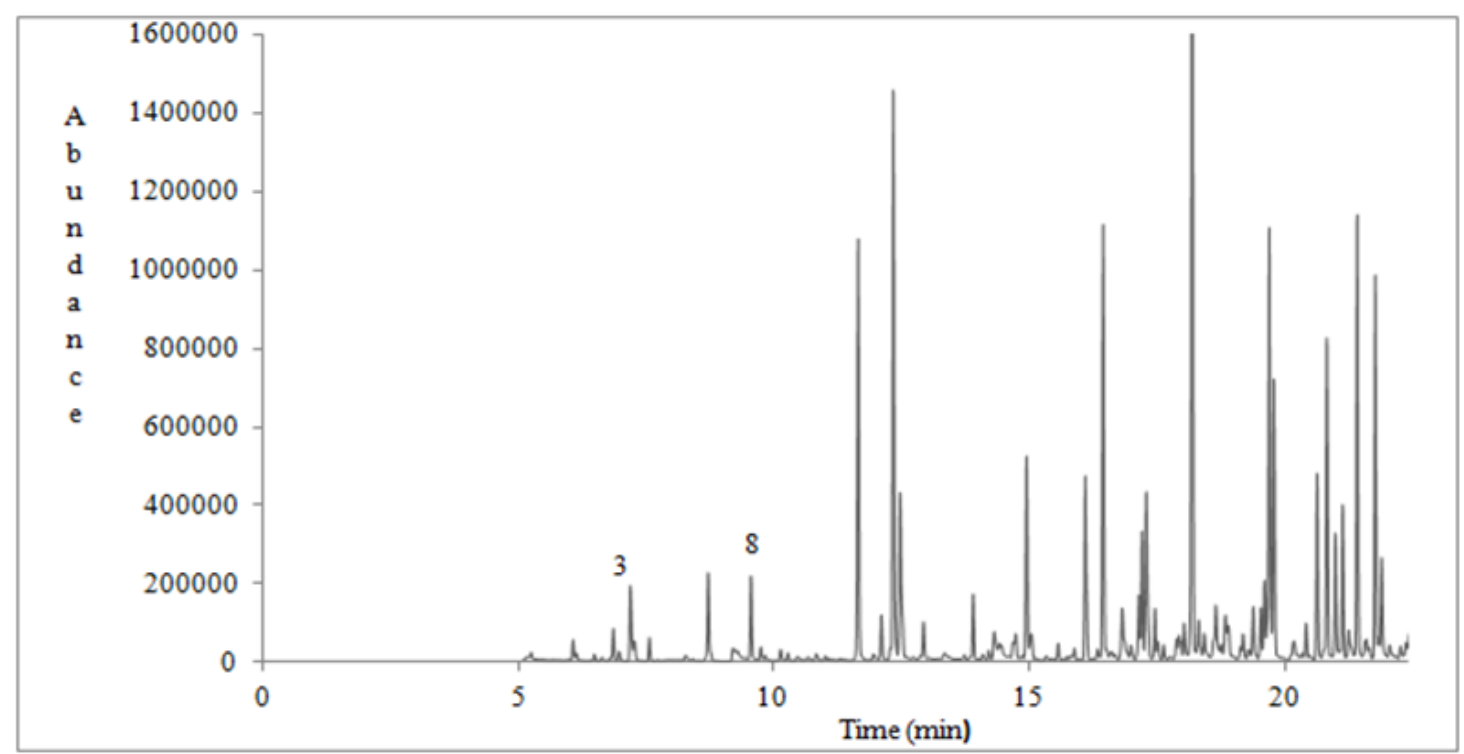




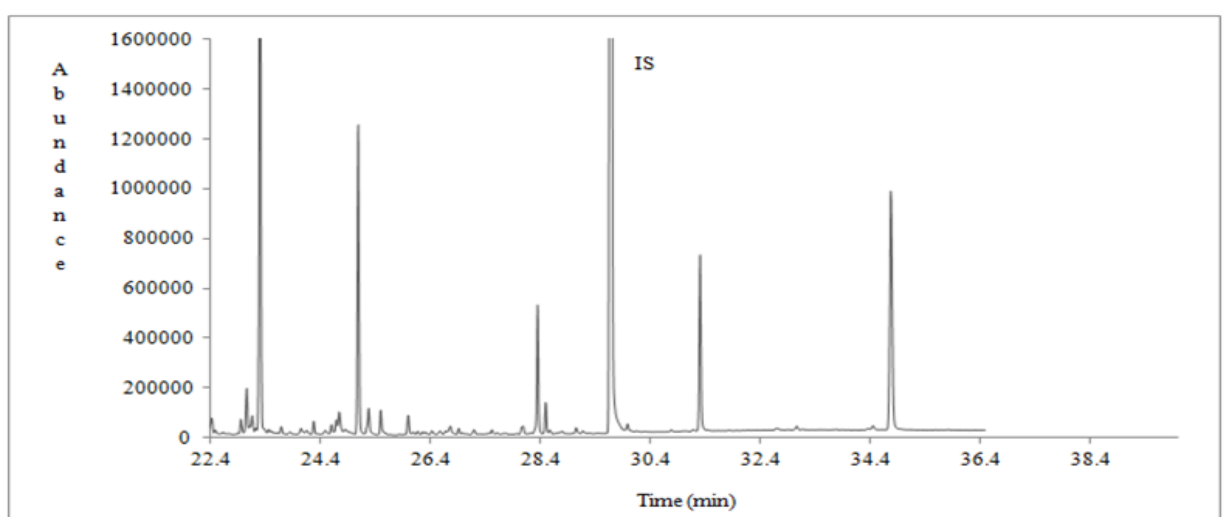

Figure 1. A typical chromatogram of commercial fir honey (no.1) from Karpenisi. Volatile markers are numbered according to Table 3.IS: internal standard.

\subsection{Classification of fir honey according to geographical origin based on physicochemical parameters, colour attributes, and volatile compounds}

The 43 fir honey samples were subjected to MANOVA analysis to determine which physicochemical parameters, colour attributes, and volatile compounds are significant for the geographical classification. Dependent variables included the 11 physicochemical parameters (including colour) and the 41 volatile compounds (with the exception of furfural) while geographical origin was taken as the independent variable.

Pillai's Trace $=1.008(\mathrm{~F}=65.581, p=0.001)$ and Wilks' Lambda $=0.001 \quad(\mathrm{~F}=71.428, p=0.002)$ index values showed the existence of a significant multivariable effect of honey physicochemical parameters, colour attributes, and volatile compounds on geographical origin of fir honey. Six physicochemical parameters (including colour) and 15 volatile compounds were found to be significant $(p<0.05)$ for the geographical classification of commercial fir honeys. Thus, these 21 parameters were subjected to LDA.

Results showed that two statistically significant discriminant functions are formed. (Wilks' Lambda $=0.001$, $\mathrm{X}^{2}=209.306, \mathrm{df}=80, p=0.001$ ) for the first function and (Wilks' Lambda $=0.032, \mathrm{X}^{2}=101.235, \mathrm{df}=57, p=0.001$ ) for the second. A significant value of Wilks' Lambda index shows that the discriminant function is basic for the differentiation of the investigated groups. Testing of the uniformity of variability (Box's $\mathrm{M}=456.712, \mathrm{~F}=2.321$, $p=0.051$ ) was insignificant at the $95 \%$ confidence level showing the existence of uniformity of sample variability for each geographical origin.

The first discriminant function accounted for $82.6 \%$ of total variance and the second accounted for $10.4 \%$. Both accounted for $93 \%$ of total variance. In Fig. 2 it is shown that all the geographical regions are well separated with Karditsa and Karpenisi being relatively close to one another. The first discriminant function clearly differentiates Karditsa and Karpenisi from all the other regions, while the second discriminant function clearly differentiates Messinia and Lakonia. The dependent variables that contributed to the first and second discriminant function, resulting to a correct geographical classification of fir honeys, are shown in Table 3.

The overall correct classification rate was $100 \%$ using the original and $69.8 \%$ the cross validation method; the latter considered a satisfactory value especially for the second "conservative" method [2].

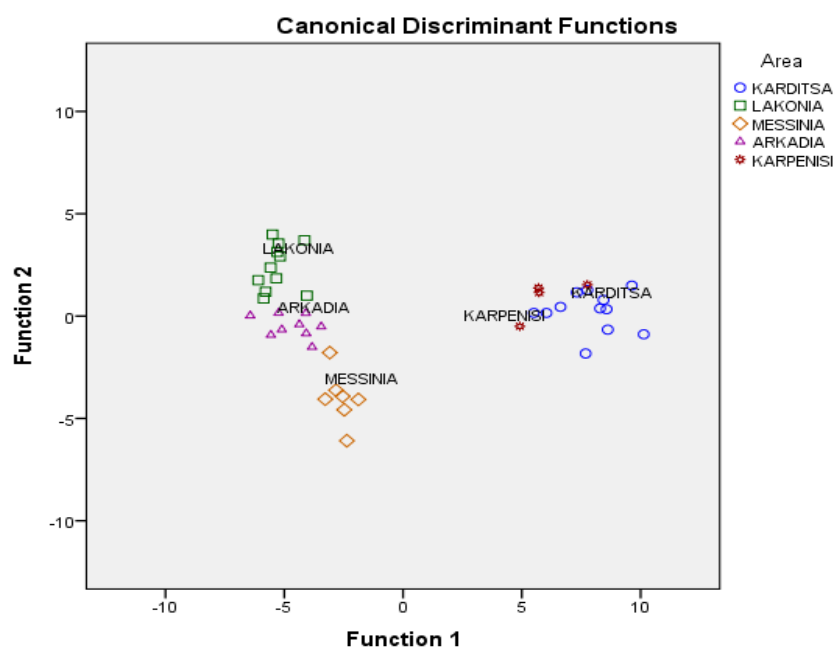

Figure 2. Geographical classification of commercial fir honeys using 21 parameters 
Table 3. Physicochemical parameters, colour attributes, and volatile compounds served as markers of fir honey geographical origin

\begin{tabular}{|l|c|c|c|c|}
\hline \multirow{2}{*}{ Markers of geographical origin } & \multicolumn{2}{|c|}{ Discriminant function } & \\
\cline { 2 - 4 } & 1 & 2 & F & $p$ \\
\hline b-Damascenone & $82.6 \%$ & $10.4 \%$ & & 0.003 \\
\hline Benzeneacetaldehyde & $-0.287^{1}$ & 0.162 & 4.865 & 0.037 \\
\hline Moisture & $-0.164^{1}$ & 0.097 & 2.844 & $<0.001$ \\
\hline Ash & $0.363^{1}$ & 0.162 & 7.063 & 0.001 \\
\hline Electrical conductivity & $0.302^{1}$ & -0.072 & 5.766 & 0.001 \\
\hline 4-keto-Isophorone & $0.302^{1}$ & -0.074 & 5.706 & 0.034 \\
\hline 1-Octene & $0.162^{1}$ & 0.099 & 2.919 & 0.005 \\
\hline 2,5-dimethyl Furan & $0.153^{1}$ & 0.047 & 4.415 & 0.020 \\
\hline Ethenyl-Benzene & $0.149^{1}$ & 0.135 & 3.310 & 0.032 \\
\hline Lactonic acidity & $0.124^{1}$ & 0.061 & 2.962 & $<0.001$ \\
\hline Octanoic acid ethyl ester & -0.191 & $0.602^{1}$ & 13.533 & 0.037 \\
\hline Acetic acid ethyl ester & 0.038 & $0.502^{1}$ & 2.839 & $<0.001$ \\
\hline Lactonic to free acidity ratio (L/FA) & -0.012 & $-0.481^{1}$ & 17.051 & 0.001 \\
\hline Heptanone-2 & -0.097 & $0.475^{1}$ & 5.858 & 0.027 \\
\hline Nonanoic acid ethyl ester & 0.036 & $0.474^{1}$ & 3.093 & 0.046 \\
\hline Undecanoic acid ethyl ester &, 013 & $0.390^{1}$ & 2.679 & 0.024 \\
\hline$a^{*}$ & -0.070 & $0.354^{1}$ & 3.192 & 0.024 \\
\hline Nonane & -0.090 & $-0.300^{1}$ & 3.181 & $<0.001$ \\
\hline Heptane & 0.256 & $0.281^{1}$ & 8.835 & $<0.001$ \\
\hline Octane & -0.034 & $-0.269^{1}$ & 12.047 & 0.009 \\
\hline 2-hydroxy-Benzoic acid methyl ester & 0.046 & $0.213^{1}$ & 3.983 & 0.007 \\
\hline Pooled win-groups correlions & 0.117 & $0.208^{1}$ & 4.164 & \\
\hline
\end{tabular}

Pooled within-groups correlations between discriminating variables and standardized canonical discriminant functions Variables ordered by absolute size of correlation within function. ${ }^{1}$ Largest absolute correlation between each variable and any discriminant function.

Present classification results, are lower as compared to those reported previously for Greek pine honeys (based on the use of physicochemical parameters and volatile compounds), and thyme honeys (based on the use of volatile compounds), respectively [2, 3]. It should also be mentioned that such data involving fir honey, has not been previously published in literature regarding Greek fir honey.

Along the same line of reasoning, Juan-Borrás et al. [4], reported a higher classification rate than that of the present work in a study involving acacia, tilia, and sunflower honeys from Spain, Romania, and Czech republic, respectively, using physicochemical parameters in combination with volatile compounds and chemometrics. At this point it should be noticed that, in the previous work of Karabagias et al. [2] and Alissandrakis et al. [3] the geographical regions investigated were 4 , and were of no close proximity as in the present study. The same holds for the work of Juan-Borrás et al. [4], which involved different honey types produced in different countries. We claim that it is more difficult to differentiate honeys from the same production country or from areas of close proximity.

\section{Conclusions}

Results of the present study showed that specific physicochemical and colour parameters, along with volatile compounds and chemometrics, may provide useful information regarding commercial fir honey geographical origin. This is the first report on such a topic, this constituting the novelty of the present work. Differences in the classification rates may be also attributed to the presence of different flowers in the proximity of the investigated regions. However, this is expected since honeybees collect nectar or honeydew from a large number of plants or trees, grown in a given area. Finally, in honey authentication efforts it should be considered that, if the tested regions or physicochemical parameters investigated increase, then correct classification rates are expected to decrease. This fact may justify the relatively low correct prediction rate recorded in the present study.

\section{Acknowledgments}

The authors would like to thank ATTIKI Honey S.A. for the donation of fir honey samples from Karditsa and Karpenisi. Technical assistance of Dr. Sofia Karabournioti in the melissopalynological analysis is greatly acknowledged. The assistance of local beekeepers from Messinia, Lakonia, and Arkadia in the collection of fir honey samples is also acknowledged.

\section{References}

[1]. P. Chaikham, V. Kemsawasd, and A. Apichartsrangkoon, Effects of conventional and ultrasound treatments on physicochemical properties and antioxidant capacity of floral honeys from Northern Thailand, Food Bioscience, 15, 2016, 19-26. 
[2]. I.K. Karabagias, A. Badeka, S. Kontakos, S. Karabournioti, and M.G. Kontominas, Characterisation and classification of Greek pine honeys according to their geographical origin based on volatiles, physicochemical parameters and chemometrics, Food Chemistry, 146, 2014, 548-557.

[3]. E. Alissandrakis, P.A. Tarantilis, P.C. Harizanis, and M. Polissiou, Comparison of the volatile composition in thyme honeys from several origins in Greece, Journal of Agricultural and Food Chemistry, 55, 2007, 8152-8157.

[4]. M. Juan-Borrás, E. Domenech, M. Hellebrandova, and I. Escriche, Effect of country origin on physicochemical, sugar and volatile composition of acacia, sunflower and tilia honeys, Food Research International, 60, 2014,86-94.

[5]. M. Bougrini, K. Tahri, T. Saidi, N. El Alami El Hassani,, B. Bouchikhi, and N. El Bari, Classification of honey according to geographical and botanical origins and detection of Its adulteration using voltammetric electronic tongue, Food Analytical Methods, 9(8), 2016,2161-2173.

[6]. Harmonized methods of the International Honey Commission (IHC).(1997). IHC responsible for the methods: Stefan Bogdanov. Swiss Bee Research Centre FAM, Liebefeld, CH-3003 Bern, Switzerland.

[7]. S. Bogdanov, C. Lullman, P. Martin, W. von der Ohe, H. Russman, and G. Vorwohl, Honey quality and international regulatory standards: Review by the International Honey Commission. Mitteilungen aus Lebensmitteluntersuchungund Hygiene, 90, 1999, $108-125$.

[8]. C. Ferrari, P. Maresca, and R. Ciccarone, The application of high hydrostatic pressure for the stabilization of functional foods: Pomegranate juice, Journal of Food Engineering, 100, 2010, 245-253.

[9]. L.P.M Pontara, E. Clemente, D.M . Oliveira, A. Kwiatkowski, C.I.L.F. Rosa, and V.E. Saia, Physicochemical and microbiological characterization of cassava flower honey samples produced by Africanized honeybees. Ciência e Tecnologia de Alimentos, 32(3), 2012, 547-552.

[10]. Council Directive 2001/110/EC relating to honey. Official Journal of the European Communities, L 10, 47-52.

[11]. S. Bogdanov, and P. Martin, Honey authenticity: a review. Mitteilungen aus dem Gebiete der Lebensmitteluntersuchung und Hygiene, 93, 2002, 232-254.

[12]. S. Sahinler, N. Sahinler, and A. Gul, Determination of honey botanical origin by using discriminant analysis. Journal of Animal and Veterinary Advances 8(3), 2009, 488-491.

[13]. A.B. Manzanares, Z.H. García, B.R. Galdón, R. Rodríguez, and C.D. Romero, Differentiation of blossom and honeydew honeys using multivariate analysis on the physicochemical parameters and sugar composition. Food Chemistry, 126, $2011,664-672$.

[14]. A. Pavelková, M. Kačániová, J. Čuboň, Z. Švecová, V. Kňazovická, and S. Felsöciová, Physicochemical and microbiological quality of honey from Liptov region. Journal of Microbiology, Biotechnology, and Food Sciences, 2(1), 2013, 1185-1193.

[15]. F. Tornuk, S. Karaman,, I. Ozturk, O.S. Toker, B. Tastemur, O. Sagdic, M. Dogan, and A. Kayacier, Quality characterization of artisanal and retail Turkish blossom honeys: Determination of physicochemical, microbiological, bioactive properties and aroma profile, Industrial Crops and Products,46, 2013, 124-131.

[16]. CIE (Commision Internationale de 1' Éclairage) Colorimetry. Technical report CIE 15.2,third ed., Viena, Austria (2004).

[17]. Z. Can, O. Yildiz, H. Sahin, E.A. Turumtay, S. Silici, and S. Kolayli, An investigation of Turkish honeys: their physico-chemical properties, antioxidant capacities, and phenolic profiles, Food Chemistry, 180, 2015, 133-141.

[18]. M. Viuda-Martos,Y. Ruiz-Navajas, J.M. Zaldivar-Cruz, V. Kuri, J. Fernández-López, Á.A. Carbonell-Barrachina, and J.Á. Pérez Álvarez, Aroma profile and physico-chemical properties of artisanal honey from Tabasco, Mexico, International Journal of Food Science and Technology, 45, 2010, 1111-1118.

[19]. Ch. Tananaki, A. Thrasyvoulou, J.L. Giraudel, and M. Montury, Determination of volatile characteristics of Greek and Turkish pine honey samples and their classification by using Kohonen self organising maps, Food Chemistry, 101, $2007,1687-1693$.

[20]. H.Z. Senyuva, J. Gilbert, S. Silici, A. Charlton, C. Dal, N. Gürel, and D. Cimen, Profiling Turkish honeys to determine authenticity using physical and chemical characteristics, Journal of Agricultural and Food Chemistry, 57, 2009, $3911-3919$.

[21]. D. Luŝić, O. Koprivnjak, D. Duŝka-Ĉrić, A.G. Sabatini, and L.S. Conte, Volatile profile of Croatian lime tree (Tilia sp.), fir honeydew (Abies alba) and sage (Salvia officinalis) honey, Food Technology and Biotechnology, 45 (2), 2007, 156-165.

[22]. L. Castro-Vázquez, M.C.Díaz-Maroto, M.A. González-Viňas, and M.S. Pérez-Coello, Differentiation of monofloral citrus, rosemary, eucalyptus, lavender, thyme, and heather honeys based on volatile composition and sensory descriptive analysis. Food Chemistry, 112, 2009, 1022-1030. 